\title{
Delayed measles mortality among exposed children who survived the epidemic of 1714-15 in New France
}

\author{
Ryan Mazan \\ Director/Territorial Statistician, Nunavut Bureau of Statistics \\ rmazan@alumni.uwo.ca
}

\begin{abstract}
This follow-up study examines delayed mortality of children under age 5 who were exposed to measles and survived the acute phase of the 1714-15 epidemic in Quebec. The objective of the study was to assess whether exposed children had higher long-term mortality than unexposed children, by following them for 25 months past the estimated date of infection. Overall, children exposed before age 3 had higher long-term mortality than unexposed children. The difference remained significant while assessing other risk factors. Delayed mortality also varied by age and sex. Only exposed female infants had a significantly higher risk of dying, while both exposed male and female toddlers had higher mortality. No significant difference was found among cbildren exposed after age 3. Findings are explained in terms of modern post-measles studies in Africa and of previous measles studies in New France.
\end{abstract}

Keywords: delayed measles mortality, epidemic, follow-up study, New France.

\section{Résumé}

Cette étude de suivie examine la mortalité différée suivant l'exposition à la rougeole pour les enfants de moins de 5 ans qui y ont été exposés mais qui ont survie la phase aigüe de l'épidémie de 1714-15 au Québec. L'objectif est de vérifier que les enfants exposés ont eu une mortalité à long terme plus élevée que les enfants non-exposés en les suivant pour une période de 25 mois après la date estimée de l'infection. Au total, les enfants exposés avant l'agge de 3 ans ont eu une mortalité plus élevée que les enfants non-exposés. La différence est statistiquement significative, même après avoir considéré d'autres facteurs de risque. La mortalité différée varie également selon l'âge et le sexe. Parmi ceux qui ont été exposés avant l'âge de 1 an, seules les filles ont eu un risque différé plus élevé, alors qu'une exposition entre 1 et 3 ans est liée à une augmentation de la mortalité différée chę les garcons comme chez les filles. Aucune différence statistiquement significative n'a été trowvée pour les enfants de plus de 3 ans. Les résultats de l'étude sont interprétés à l'aune d'études contemporaines sur la rougeole en Afrique et d'études précédentes sur la maladie en Nouvelle-France.

Mots-clés : mortalité par rougeole différée; épidémie; étude de suivi: Nouvelle-France.

\section{Introduction}

Measles caused a considerable number of childhood fatalities in New France during the 1714-15 epidemic. The present study is the third of a series. In the first, the general characteristics of the epidemic were described at the aggregate level (see Mazan et al. 2009). A series of smoothing splines were fit to the time-series data by age, sex, and region, in order to estimate measles mortality and to trace the origin, spread, duration, and severity of the epidemic. It was found that the epidemic originated in the western part of the colony, in the Montreal area, in late March of 1714. By September, the epidemic had spread to all parts of the colony and had run its course in early 1715 . Measles were generally severe among children under 15 years of age, but severity declined with age and varied by sex and region. Children in the eastern parishes had the highest risk of death, while females were more likely than males to have died 
from the virus. The aggregate study of the epidemic served as a benchmark for determining the study population of a more detailed analysis on the identification of risk factors associated with measles mortality at the individual level.

The objectives of the second study were twofold (see Mazan 2011). First, methods were developed to identify children who were most likely exposed to measles. The second objective was to identify risk factors for measles mortality among exposed children during the acute episode of the epidemic, by making comparisons with control groups subject to normal mortality conditions. Although there was no direct method to partition measles and non-measles deaths, these indirect methods helped clarify the possible role that demographic and familial risk factors played during the measles epidemic. Important risk factors included the estimated age at infection, death of one or more sibling(s) in the family, immigrant status of the parents, age difference between siblings, sibship size, and the region of residence. The first two studies served as benchmarks for developing further methods to analyze the long-term fate of the French Canadian children who were exposed to the measles virus, which is the subject of this third study.

Not only are exposed children at a high risk of death within the first weeks of becoming infected, they are also believed to be at a high risk of dying for a considerable time afterwards. Typically, delayed measles mortality has been defined as a death occurring at least 30 to 43 days past infection (Aaby et al. 1996). The period of susceptibility is believed to last from several weeks to several months after the onset of rash, and is attributed to a prolonged state of immune suppression and an increased susceptibility to secondary infections. This is characterized by a failure to thrive, recurrent infections, persistent pneumonia, and diarrhoea. Vitamin A deficiency has also been implicated as a contributing risk factor (Hull et al. 1983; Aaby and Clements 1989; Clements and Hussey 2004).

Studies conducted in West Africa have found evidence of an increased risk of delayed measles mortality. Hull et al. (1983) found that exposed children in Gambia had a significantly higher risk of dying after the acute phase of infection, compared with community controls. Delayed mortality was found to be higher among exposed infants than for older children who were exposed to the virus. Another Gambian study, however, found that exposed toddlers (12 to 35 months) also had higher long-term mortality than unexposed controls (Hull 1988).

Similarly, studies in Guinea-Bissau have even found that infants who were exposed to measles during the first six months of life were three to four times more likely to die than community controls during a 60-month follow-up period (Aaby et al. 1990, 1993; Aaby 1995). The delayed effect lasted for up to 3 years past initial exposure, and was present even if the infants did not develop clinical measles. In populations where measles epidemics are frequent, placental transferred antibodies provide protection from measles infection for infants less than 9 months old, if their mothers acquired immunity through natural infection or immunization. Due to the protection afforded by maternal antibodies, acute infection would usually be less severe if infants contracted measles after intensive exposure from an older sibling and, in turn, would have had a relatively high recovery rate (Aaby et al. 1996).

Despite the protection acquired from maternal antibodies, findings from the studies in Guinea-Bissau suggest that measles exposure before 6 months was an important risk factor of long-term mortality. Aaby et al. (1995) indicate that little is known about delayed mortality after acute measles infection, including possible confounding factors, determinants, and underlying mechanisms. As is the case for older children, intensive exposure and a high dose of infection during early infancy may be important to the disease process. Children who were exposed to measles before 6 months of age are likely to have been exposed intensively at home from repeated contact with an older sibling (Garenne and Aaby 1990). The higher dose of the virus may induce latent infection, malnutrition, and growth faltering (i.e., failure to thrive) later on in childhood.

Not all studies have found support for the delayed mortality effect after the acute phase of infection. Aaby et al. (1995) indicated that previous studies might have "exaggerated" the delayed effect, as some of those studies compared post-measles cases with immunized children rather than with unimmunized and unexposed children. The researchers followed further on this assumption by reanalyzing data from several community studies in Senegal, Guinea-Bissau, and Bangladesh. Contrary to the findings from the earlier studies, there was no evidence of a delayed effect in any of the regions. In Guinea-Bissau and Bangladesh, post-measles cases had a significantly lower risk of dying, while in Senegal post-measles cases had a similar risk of dying compared with unimmunized children in the community. Dollimore et al. (1997) did not find increased post-measles mortality in their study of epidemics in Ghana between 1989 and 1991. Likewise, no support of a delayed effect was found among children in Burundi (Chen at al. 1994).

It was argued that children who survived the acute phase of infection actually might incur a survival advantage compared with unimmunized, unexposed children. Both natural measles infection and immunization may have "nonspecific beneficial effects," presumably due to immunological stimulation and an increased resistance to general infections (Aaby et al. 1995). However, the results of those studies can come into question, as the mean age of infection 
Mazan: Delayed measles mortality among exposed children who survived the epidemic of 1714-15 in New France

in those studies was over 40 months (Dollimore et al. 1997; Perry and Halsey 2004). A higher mean age at infection is usually associated with a lower case fatality rate, because older children have a better chance of recovery, due in part to a more mature immunological response.

Historical data from Quebec provide an ideal research context to examine the above contradictions on delayed mortality after measles exposure. They contain detailed information that allows for the analysis of time to death during a follow-up period. Further, the 1714-15 epidemic was the first confirmed measles epidemic in the colony, which means that Canadian-born children probably had no acquired immunity to the virus. The lack of previous exposure also means that there were enough exposed and infected children to generate a sufficiently large number of deaths. Most of the community studies conducted in West Africa were indeed based on a small number of subjects, making the reliability of their parameter estimates uncertain at times.

Finally, this study takes advantage of the fact that modern medicine, measles immunization, and public health in general were nonexistent in pre-industrial Quebec. Aaby et al. (1995) indicated that if natural measles and immunization have "non-specific" beneficial effects, the best comparison for determining the extent of post-measles mortality would be against "unimmunized and unexposed children" and, as such, historical Quebec provides an ideal setting to study the delayed effects of mortality.

This study examines the above assumptions relative to delayed measles mortality among a cohort of children exposed before age 5 by a comparison with two flanking cohorts (1708 and 1721) not exposed to measles in the first five years of life. It also builds upon the previous two studies on measles in New France by extending the selection and estimation methods to help determine the starting point of delayed mortality and identifying the individuals who died during the post-measles phase. Using life tables and multivariate Cox proportional hazards models, exposed children are followed for up to 25 months past the estimated date of infection. In general, the objective is to assess whether exposed children had a different long-term survival outcome compared to an unexposed cohort, while assessing the effects of the estimated age at infection, sex, urban/rural residence, immigrant status of parents, and sibship composition.

\section{Data and methods}

The data for this follow-up study derives from the Registre de la population du Québec ancien, compiled by the Programme de recherche en démographie historique (PRDH) at the Université de Montréal (Légaré 1988; Charbonneau et al. 1993), a reliable and accurate source established on the basis of the excellent series of parish registers available. The database contains the date and place of birth, death and marriage(s), names of parents and spouse(s), and secondary information on places of residence and of origin for individuals who lived in the St. Lawrence Valley during the 17th and 18th centuries. This valuable data has already served to address the familial component of longevity and the long-term consequences of exposure to epidemics, using survival models (Mazan and Gagnon 2007; Gagnon and Mazan 2009).

The population remained quasi-closed until the 19th century because of particular historical and geographical circumstances, and thus the usual problem of missing observations due to migration is greatly reduced (Charbonneau et al. 1993; Desjardins 1996). As the development of the database is still in progress, the available information varies in time according to the date of the events and the period of birth and marriage of the individuals. Births are matched with individuals and their parents up to 1799, and deaths up to around 1850 for individuals born before 1750. All ancestors of every individual who married before 1800 can be traced back to the founders of the population.

\section{Study population}

Since the purpose is to conduct a follow-up study of exposed children under age 5 who survived the acute phase of infection (i.e., from around late August to mid-November 1714), the selection of cases is a continuation from the previous studies (Mazan et al. 2009; Mazan 2011). The same parishes were used to select the children for this study. ${ }^{1}$ Children from these parishes were most likely exposed, as death rates were well above normal in those areas during the acute episode. However, the current study only considers children with at least one sibling during the epidemic, as one of the main focuses is on relations between siblings. The study also uses the date of infection (as determined

1. The parishes selected for the analysis were: Notre-Dame-de-Montréal; Rural West (Boucherville, Pointe-aux-Trembles, Laprairie, St.-François de Sales, Varenne, and St-François-du-Lac); Notre-Dame-de-Québec, Greater Québec Area (Beauport, L'Ancienne Lorette, Charlesbourg, and Ste-Foy); Rural East (Beaumont, Rivière-Ouelle, L'Islet, St-Thomas, Ste-AnnedeBeaupré, Château-Richer, Cap-Santé, Neuville, Ste-Famille, St-Laurent, St-Pierre, St-François, and St-Jean). 
in the previous study) to help determine the minimum entrance date for the follow-up period, or what constitutes the starting point of delayed mortality. This section reviews the procedure for estimating the date of infection, and expands upon the previous work to help identify whether cases qualify as delayed deaths.

One of the main objectives of the study design is to estimate the starting point of delayed mortality. Acute measles mortality is defined as a death taking place within 30 to 43 days from the onset of the measles rash (12 to 14 days after exposure), depending on the study (Wolfson et al. 2009). Delayed mortality is defined as a death that takes place at least 30 days after the appearance of the rash (i.e., in this study, the date of infection). The problem to overcome is that there is no direct way to know the precise time when these children were infected. However, based on the following observations and previous studies, the general time when the infection began can be approximated on a regional basis. Once the date of infection is estimated, the starting point of delayed mortality can also be estimated for each individual.

The timeline for the date of measles infection was derived from an average scenario based on the natural course of the disease. The incubation period for measles lasts from 8 to 12 days before the onset of signs and symptoms, and the measles rash appears from 12 to 14 days after initial exposure. Complications typically occur within the first week of the onset of signs and symptoms. If there are no complications, recovery begins soon after the appearance of the rash (Perry and Halsey 2004). The estimated time at infection in this study starts after the incubation period, as the appearance the measles rash is the starting point to estimating whether a death should be classified as acute or delayed (Aaby 1995). There is a limited amount of literature on the time from infection until death, but one study found that most acute deaths occurred within 1 to 2 weeks of the onset of the measles rash (Joshi et al. 2009).

As follows, the date of infection was estimated using the date of death distribution among the children who died during the acute phase between late August and mid-November. For children who died, a two-week lag period was applied when estimating the time from infection until death. For example, individuals who died in the 38th week of 1714 were assumed to have developed the rash during the 36th week. Neonatal deaths were excluded from this process. It was assumed that surviving family members were infected around the same time, and they were also assigned the same date of infection. An average date of infection was estimated for the remainder of the families with no deaths. These dates were estimated with the date of death distributions for each of the regions, as the epidemic entered the various regions at slightly different times (see Mazan et al. 2009). Infection dates among these children was assumed to follow the regional distribution where they resided.

Initially, a child had to survive at least 30 days past the estimated date of infection to be considered to have died from delayed measles mortality (if they died during the follow-up period). Upon further analysis, an additional twoweek lag period was added to account for deaths occurring too soon after the initial 30 day cutoff. The additional lag period increases the time of a delayed death to 43 days past the estimated date of infection. This time period of six weeks is also commonly used as a cutoff point between acute and delayed deaths (Wolfson et al. 2009). The extra time or penalty was applied to reduce the likelihood of a false positive classification, as estimation is based on an average scenario of the natural course of measles. If some cases were actually infected at a later time than was estimated (i.e., closer to the tail of the distribution), there is a likelihood that some may have been acute deaths. The extra time was added to reduce the chances of that occurring.

Based on the above selection criteria, the cohort of children exposed before 5 years of age could have entered the study between mid-August and the end of October 1714, given that they survived at least 43 days past the estimated date of infection $(\mathrm{N}=1,805)$. The earliest time for a death to be considered as a delayed death occurred during October of that year-after the mortality peak characterizing the acute phase, was on the decline (see Mazan et al. 2009). The exposed cohort was followed until death or up to 25 months past the estimated date of infection (to mid-November 1716), where survivors were censored at that time. The follow-up period was stopped at that date because an epidemic occurred between the end of November 1716 and early February 1717. This epidemic was not included in the follow-up period because any deaths that occurred during that time may have been unrelated to the prior measles epidemic. ${ }^{2}$

2. Based on historical accounts, Duffy (1953) indicated that there was an influenza-type epidemic in the area of Charleston, VA, in late December 1716. Further analysis needs to be done on this particular epidemic to find out what really happened, but I will assume that the epidemic in Quebec was also influenza. When the flu epidemic hit the colony, the exposed cohort ranged from 2 to 5 years of age, and mortality was generally at normal levels by that time. The outbreak started in Western Quebec in late fall and spread eastward by early winter. The epidemic was relatively short-lived, where deaths peaked for a few weeks in each area and then dissipated. 
Mazan: Delayed measles mortality among exposed children who survived the epidemic of 1714-15 in New France

The same criteria were used to select unexposed cohorts (1708 and 1721) living through periods with no known epidemic, as a basis of comparison. Selecting the cohorts before and after the epidemic provides a more conservative comparison, as it accounts for the secular increasing level of child mortality that took place during the 18th century (see Gagnon and Mazan 2009; Amorevieta-Gentil 2010). The 1721 cohort had a higher level of child mortality than the 1708 cohort, as the level began increasing in Montreal after the measles epidemic (see Mazan et al. 2009). Despite the increasing child mortality, the two unexposed cohorts had similar survival outcomes over the course of the follow-up period. There were no significant differences in survival by age and sex. Therefore, in order to facilitate comparisons and stabilize estimates, the 1708 and 1721 cohorts were combined $(\mathrm{N}=3,999)$.

The pooled unexposed cohort served to increase the reliability of the estimates, as the measures were based on a smaller number of events (deaths) than in the previous study. This is a common problem in this type of study (i.e., higher variability in some parameter estimates due to the small number of events). Although the number of events was small and created limits on the number of controls that could be included, the parameter estimates were stable in most circumstances. The exposed cohort was also tested against other cohorts (e.g., 1707, 1709, 1722, and 1723) besides the one used in the study, with no appreciable differences (not shown here). The unexposed cohorts selected for the study represented typical mortality conditions for that time, in as much as "typical" meant "years without notable epidemics." As determined elsewhere, there was little difference between the observed and expected death rates when a spline was fit through the mortality times-series data (Mazan 2011).

\section{Risk factors}

The same controls were used as in the previous study that identified some risk factors associated with measles mortality during the acute episode (see also Mazan 2011 for more details on the risk factors). The following risk factors were found to be important predictors of mortality during the acute episode of the epidemic, and some also during normal periods. Since there were fewer events (deaths) during the follow-up than in the acute episode, the categories of some of the risk factors were collapsed, in order to lessen the number of parameters to be estimated in the multivariate models. As the objective of the study was to examine the impact of the epidemic after it ended, it was more important to retain a reliable estimate of mortality.

The region of residence at the time of the epidemic was included to capture urban/rural differences in mortality, with children residing in the rural areas as the reference category. As with many infectious and parasitic diseases, the risk of death from measles has a largely predictable age pattern. The age at estimated time of infection was divided into 4 groups to reflect this pattern: $<6$ months, $<2$ months, 12 to 35 months, and 36 to 59 months. Individuals who were exposed during infancy served as the reference category in the overall model. Two variations of infancy are explored to provide a comparison to the Aaby et al. studies of early life exposure ( $<6$ months) and the Hull (1988) study of exposure during infancy ( $<12$ months). Models were also examined, with each age group analyzed separately, to find whether exposed children at different ages had higher or the same mortality as the unexposed cohort.

The sex of the child was included as a risk factor in the models, with females as the reference category. Some models were run separately for each of the sexes in order to check if age-specific exposure was different among the male and female cohorts. The immigrant status of the parents was also included, to measure whether the lower survival outcome of children with immigrant parents noted for the acute phase in Mazan (2011) extended into the post-measles phase. Immigrant status of parents was divided into 2 groups: Canadian-born and either/both parent(s) immigrated. Children with Canadian-born parents served as the reference category.

The sibling composition controls include the age difference between siblings and the death of a sibling during the acute phase. As mentioned above, it has been found that older siblings (index cases) may increase the risk of measles death among their younger siblings (secondary cases) by introducing and secreting a higher dose of the virus to those children. However, there is no information on the behaviour of this measure during the post-measles period. This factor was estimated by subtracting each child's age at time $x$ from the average age of the sibship at time $x$. The average age difference was then coded as $<4$ years and $4+$ years, with $4+$ years serving as the reference group.

The death of a sibling during the acute phase serves as a proxy for the incidence of multiple and secondary cases in a given family. As mentioned in a prior study, this measure may be a good alternative when information is lacking on secondary cases (Mazan 2011), which have been found to be at the highest risk of death during an epidemic (i.e., dose response effect) and afterwards (Aaby 1995). If there is a death in the family, then it could be an indication of severe infection in the household. Individuals without a dead sibling during the given period 
Table 1. Description of the categorical variables included in the multivariate Cox proportional hazards models for children exposed before the age of 3 years and the unexposed comparison cohort, New France.

\begin{tabular}{|c|c|c|c|}
\hline Risk Factor & Exposed vs. Unexposed & Exposed (1714) & Unexposed $(1708,1721)$ \\
\hline Total & 3,552 & 1,071 & 2,481 \\
\hline \multicolumn{4}{|l|}{ Cohort } \\
\hline Exposed & 1,071 & - & - \\
\hline Unexposed $\dagger$ & 2,481 & - & - \\
\hline \multicolumn{4}{|l|}{ Residence } \\
\hline Urban & 1,081 & 309 & 772 \\
\hline Rural $\dagger$ & 2,471 & 762 & 1,709 \\
\hline \multicolumn{4}{|l|}{ Sex } \\
\hline Male & 1,728 & 560 & 1,168 \\
\hline Female $\dagger$ & 1,824 & 511 & 1,313 \\
\hline \multicolumn{4}{|l|}{ Age at Exposure } \\
\hline$<12$ months $\dagger$ & 1,300 & 392 & 908 \\
\hline $12-23$ months & 1,109 & 317 & 792 \\
\hline 24-35 months & 1,143 & 362 & 781 \\
\hline \multicolumn{4}{|l|}{ Immigrant Status } \\
\hline Immigrant Parent(s) & 1,114 & 329 & 785 \\
\hline French Canadian† & 2,438 & 742 & 1,696 \\
\hline \multicolumn{4}{|l|}{ Age Difference } \\
\hline$<4$ years & 1,955 & 636 & 1,319 \\
\hline $4+$ years $\dagger$ & 1,597 & 435 & 1,162 \\
\hline \multicolumn{4}{|l|}{ Sibling Survival } \\
\hline Sibling Died & 217 & 112 & 105 \\
\hline No Death $\dagger$ & 3,335 & 959 & 2,376 \\
\hline
\end{tabular}

$\uparrow$ Reference category - basis of comparison for the other categories.

formed the reference group. Table 1 summarizes the coding of the controls and gives the number of families in each category used for the Cox proportional hazards models.

\section{Life Tables and Proportional Hazards Models}

To improve comparability, statistical models were used that were similar to the ones used in the series of studies conducted by Aaby and colleagues_Life Tables and Cox Proportional Hazards Models. Preliminary comparisons of survival between the exposed and unexposed cohorts were done using discrete or clinical life tables. The survival times of each of the children were subdivided into 24 discrete monthly intervals (e.g., 0-1, 1-2, ..., 24-25) by exposure status, age, and sex. The life table takes on the general actuarial form:

$$
q_{x}=d_{x} / N_{x} \text { and } \quad p_{x}=\left(1-q_{x}\right)
$$

where $q_{x}$ is the probability of dying in the monthly interval $x$ to $x+n$, where $d_{x}$ is the number dying in the monthly interval $x$ to $x+n, N_{x}$ is the size of the cohort, and $p_{x}$ is the conditional probability of surviving or the complement of $q_{x}$. In this study, only the summary probabilities of dying are presented for each of the groups based on the entire follow-up period (i.e., probability of dying between 0 to 25 months) to facilitate comparisons (see Table 2). Mantel-Haenszel $(\mathrm{M}-\mathrm{H})$ hazards ratios and significance tests were used to compare the life table survival of the exposed and unexposed cohorts (see Breslow and Day 1987 and Esteve and Raymond 1994 for a formal treatment of the M-H procedure).

For the multivariate models, a series of Cox regression models were fitted in order to assess whether the predictors had any influence on the individual's survival time. The Cox regression model expresses a transformation of the hazard as a linear function of the predictors. A continuous hazard function is a rate with no upper bound ( $\infty$ ) and thus, the logarithm of the hazard is treated as the outcome variable (Singer and Willet 2003: 514):

$$
\log h\left(t_{i}\right)=\log h_{o}(t)+\left[\beta_{1} X_{1}+\beta_{2} X_{2}+\ldots+\beta_{i} X_{i}\right] .
$$

The $\log$ hazard $\left(\log h\left(t_{i}\right)\right)$ equals the baseline function $\left(\log h_{0}(t)\right)$, or when the covariates equal 0 , plus a weighted linear combination of predictors $(\beta)$ that measure the effect of the covariates on $\log h\left(t_{i}\right)$. The main assumptions of the Cox proportional hazards model are: (1) a log-linear relationship between the covariates and the underlying hazard function and; (2) a multiplicative relationship between the underlying hazard function and the log-linear 
function of the covariates (Blossfeld et al. 1989). It is assumed that the hazard function of any two individuals have parallel age (time) patterns (Namboodiri and Suchindran 1987; Elandt-Johnson and Johnson 1980). All of the covariates included in the models appeared to meet the proportionality assumption. ${ }^{3}$ Since the data contain correlated observations or the possibility of temporal dependence among groups of individuals (i.e., siblings), the standard errors of the coefficients were adjusted using robust variance estimation. This procedure involves relaxing the temporal independence assumption by accounting for the clustering of observations, here by sibships (siblings were identified as individuals having the same mother).

\section{Results}

In this section, the results of the life tables and Multivariate Cox Proportional Hazards models are presented for the 25-month follow-up period comparing the survival outcome of the exposed and unexposed cohorts. In general, most children in both the exposed and unexposed cohorts survived the follow-up period. However, the risk of death for the exposed cohort was higher during that time.

\section{Life Tables}

Table 2 gives the summary statistics of 30 clinical life tables for the 25 -month follow-up period for the exposed and unexposed cohorts by the estimated age at infection or observation period for the unexposed cohort and by sex of the child. The Mantel-Haenszel hazard ratios are also provided to give a comparison of the overall difference in mortality between the exposed and unexposed cohorts over the follow-up period. Overall, the probability of dying within the follow-up period declined with age for both cohorts. This pattern is expected, as it follows the empirical age pattern of mortality at the younger ages (i.e., exponential decline). For instance, 13.5\% of children exposed to measles during infancy died within 2 years after exposure, $7.7 \%$ of exposed toddlers (12 to 35 months) died within 2 years, and so forth. In general, survival among the exposed cohort was lower for all age groups, with the exception of older children who were exposed between 36 and 59 months of age. ${ }^{4}$

After adjusting for the estimated age at infection/observation, children exposed before 3 years of age were 1.62 times more likely to die within the 25 -month follow-up period than the unexposed cohort $(\mathrm{p}<.001)$. In total, $9.8 \%$ of children exposed before 3 years of age died, as compared to $6.2 \%$ of unexposed children during the follow-up period. The overall delayed effect appeared stronger for females exposed before age 3 than exposed male children $\left(\mathrm{HR}_{\mathrm{M}-\mathrm{H}}=1.79, \mathrm{p}<.01\right.$ vs. $1.49, \mathrm{p}<.05$, respectively).

Exposed infants (less than 12 months) had a slightly higher probability of dying than unexposed children, but the difference did not reach statistical significance $\left(\mathrm{HR}_{\mathrm{M}-\mathrm{H}}=1.29, \mathrm{p}>.05\right)$. When testing the sex-specific risk, the reason for the non-significant effect becomes apparent. Exposed and unexposed male infants had the same risk of dying

Table 2. Summary statistics of the 25-month follow-up life tables for children exposed to measles and the unexposed cohort by age and sex, New France.

\begin{tabular}{|c|c|c|c|c|c|c|c|c|c|}
\hline \multirow{3}{*}{$\begin{array}{c}\text { Age at } \\
\text { Infection }\end{array}$} & \multicolumn{3}{|c|}{ Total } & \multicolumn{3}{|c|}{ Males } & \multicolumn{3}{|c|}{ Females } \\
\hline & \multicolumn{2}{|c|}{$\begin{array}{l}\text { Probability of dying in } \\
\text { follow-up }\left({ }_{n} q_{x}\right)\end{array}$} & \multirow{2}{*}{$\begin{array}{l}\text { Mantel- } \\
\text { Haenszel } \\
\text { Hazard } \\
\text { Ratio } \\
\end{array}$} & \multicolumn{2}{|c|}{$\begin{array}{l}\text { Probability of dying in } \\
\text { follow-up }\left({ }_{n} q_{x}\right)\end{array}$} & \multirow{2}{*}{$\begin{array}{l}\text { Mantel- } \\
\text { Haenszel } \\
\text { Hazard } \\
\text { Ratio }\end{array}$} & \multicolumn{2}{|c|}{$\begin{array}{l}\text { Probability of dying in } \\
\text { follow-up }\left({ }_{n} q_{x}\right)\end{array}$} & \multirow{2}{*}{$\begin{array}{l}\text { Mantel- } \\
\text { Haenszel } \\
\text { Hazard } \\
\text { Ratio }\end{array}$} \\
\hline & Exposed & Unexposed & & Exposed & Unexposed & & Exposed & Unexposed & \\
\hline$<12$ & 0.135 & 0.113 & 1.29 & 0.137 & 0.137 & 1.01 & 0.133 & 0.078 & $1.76^{*}$ \\
\hline $12-35$ & 0.077 & 0.036 & $2.16^{* * *}$ & 0.089 & 0.038 & $2.41^{* * * *}$ & 0.064 & 0.034 & $1.91^{*}$ \\
\hline $36-59$ & 0.022 & 0.026 & 0.85 & F & F & F & F & F & F \\
\hline$<36$ & 0.098 & 0.062 & ${ }^{\mathrm{a}} 1.62^{* * *}$ & 0.107 & 0.076 & a $1.49^{*}$ & 0.088 & 0.050 & a $1.79^{* *}$ \\
\hline$<6$ & 0.180 & 0.132 & $1.41^{*}$ & 0.169 & 0.149 & 1.15 & 0.191 & 0.113 & $1.77^{*}$ \\
\hline \multicolumn{10}{|c|}{$\begin{array}{l}\mathrm{p}<.001^{* * *}, \mathrm{p}<.01^{* *}, \mathrm{p}<.05^{*} \\
{ }^{\mathrm{F}} \text { High sampling variability. } \\
\text { a Adjusted for age at infection/observation. }\end{array}$} \\
\hline \multicolumn{10}{|c|}{$\begin{array}{l}\text { 3. Any potential violations of the proportionality assumption were checked with } \log [S(t)] \text { plots of the categorical variables } \\
\text { and Schoenfeld residual plots of all covariates. The covariates showed no deviation from time invariance. Additionally, } \\
\text { there were no significant correlations between the Schoenfeld residuals and time (age at death) for each of the covariates. } \\
\text { 4. Given that reliability is a problem with the older children, and that they had the same mortality as unexposed children, } \\
\text { only children exposed before the age of } 3 \text { were considered for the overall hazard ratio and later in the multivariate models }\end{array}$} \\
\hline
\end{tabular}


during the follow-up period $\left(\mathrm{HR}_{\mathrm{M}-\mathrm{H}}=1.01, \mathrm{p}>.05\right)$. Exposed female infants, on the other hand, had a significantly higher risk of dying than unexposed females $\left(\mathrm{HR}_{\mathrm{M}-\mathrm{H}}=1.76, \mathrm{p}<.05\right)$. Similarly, females exposed before 6 months were 1.77 times more likely to die than unexposed infants $(\mathrm{p}<.05)$, as compared to infants subjected to normal conditions. Almost one-fifth (19.1\%) of females exposed before 6 months of age died within the 25 -month follow-up period, while $11.3 \%$ of unexposed female infants died. These exposed female infants even had a slightly higher probability of dying than both exposed and unexposed males (16.9\% and 14.9\%, respectively).

For exposed toddlers, the risk of dying was twofold $\left(\mathrm{HR}_{\mathrm{M}-\mathrm{H}}=2.16, \mathrm{p}<.001\right)$. Both exposed male and female toddlers had a significantly higher risk of death, but the magnitude of the effect was stronger for males $\left(\mathrm{HR}_{\mathrm{M}-\mathrm{H}}=2.41\right.$, $\mathrm{p}<.001$ and 1.91, $\mathrm{p}<.05$, respectively). Around $8.9 \%(.089 \times 100)$ of exposed male toddlers died and $6.4 \%$ of exposed females died during follow-up, as compared to $3.8 \%$ and $3.4 \%$ of unexposed male and female toddlers, respectively. The survival of children exposed past 3 years of age was not significantly different from the survival of unexposed children. These probabilities are based on fewer events than the corresponding figures at younger ages, and it was not possible to obtain a reliable estimate for each of the sexes.

\section{Proportional Hazards Models}

Although Table 2 shows that exposed children had a higher risk of dying than unexposed children during the follow-up period, the analysis was conducted without an assessment of the other risk factors. To further test the delayed measles effect, Table 3 shows the Hazard ratios (HR) and asymptotic standard errors (ASE) of the multivariate proportional hazards models (A through C) for each age at infection/observation and sex, while assessing the effects of the other demographic and sibship factors. Even when controlling for the other effects, the age and sex-specific hazard ratios remain similar to the life table ratios in Table 2. The hazard ratios between the exposed and unexposed cohorts actually increase slightly with the inclusion of the other factors in the models.

Overall, children who were exposed to measles before 3 years of age had a significantly higher risk of dying during the 25-month follow-up period than the unexposed cohort, while assessing the effects of the demographic and sibship factors $(\mathrm{HR}=1.68, \mathrm{p}<.001)$. Both males and females exposed to measles before 3 years of age also had a significantly higher risk of dying within the follow-up period than unexposed children. The post-measles effect remained stronger for females, as they had close to double the risk, while males had a $53 \%$ higher risk of dying $(\mathrm{HR}=1.91, \mathrm{p}<.01$ and $\mathrm{HR}=1.53, \mathrm{p}<.05$, respectively). The rest of ratios in Table 3 are not interpreted, since the patterns are identical to the ratios derived from the life table models presented in Table 2.

Table 4 gives the Hazard ratios (HR) and the robust standard errors (RSE) of the multivariate proportional hazards models (D through F) for the 25-month follow-up period of the exposed (1714) and unexposed cohorts (1708, 1721). Model $\mathrm{D}$ includes both the exposed and unexposed cohort with all of the risk factors entered simultaneously. Models $\mathrm{E}$ and $\mathrm{F}$ show the exposed and unexposed cohorts individually to assess the impact that the demographic and sibship factors had on each of the groups. Bootstrap hazard ratios $\left(\mathrm{HR}_{\mathrm{BS}}\right)$ are also provided to demonstrate the stability of the parameter estimates and as a check for bias in the models. Bootstrap coefficients were obtained by randomly selecting one child from each family 100 times with replacement.

Table 3. Multivariate Cox proportional hazard models for the exposed and unexposed cohorts during the 25-month follow-up period by age and sex, New France.

\begin{tabular}{|c|c|c|c|c|c|c|c|}
\hline \multirow{2}{*}{$\begin{array}{l}\text { Age at } \\
\text { Infection } \\
\text { (months) }\end{array}$} & \multirow{2}{*}{ Cohort } & \multicolumn{2}{|c|}{$\begin{array}{c}\text { Model A } \\
\text { All Children } \\
\end{array}$} & \multicolumn{2}{|c|}{$\begin{array}{c}\text { Model B } \\
\text { Males }\end{array}$} & \multicolumn{2}{|c|}{$\begin{array}{l}\text { Model C } \\
\text { Females }\end{array}$} \\
\hline & & $\mathrm{HR}$ & ASE & HR & ASE & HR & ASE \\
\hline$<12^{\mathrm{a}}$ & $\begin{array}{l}\text { Exposed } \\
\text { Unexposed } \dagger\end{array}$ & 1.37 & 0.173 & 1.04 & 0.229 & $1.84^{*}$ & 0.270 \\
\hline $12-35^{\mathrm{a}}$ & $\begin{array}{l}\text { Exposed } \\
\text { Unexposed } \dagger\end{array}$ & $2.12^{* * *}$ & 0.194 & $2.34^{* *}$ & 0.265 & $1.91^{*}$ & 0.289 \\
\hline$<36^{\mathrm{b}}$ & $\begin{array}{l}\text { Exposed } \\
\text { Unexposed } \dagger\end{array}$ & $1.68^{* * *}$ & 0.128 & $1.53^{*}$ & 0.169 & $1.91^{* *}$ & 0.197 \\
\hline$<6^{\mathrm{a}}$ & $\begin{array}{l}\text { Exposed } \\
\text { Unexposed } \dagger\end{array}$ & $1.52 *$ & 0.193 & 1.28 & 0.265 & $1.79^{*}$ & 0.288 \\
\hline
\end{tabular}

†Reference category - basis of comparison for the other categories.

$\mathrm{p}<.001^{* * *}, \mathrm{p}<.01^{* *}, \mathrm{p}<.05^{*}$

${ }^{a}$ Controls include: residence, immigrant status, age difference between siblings and dead sibling.

${ }^{\mathrm{b}}$ Controls are the same as in Table 4. 
Table 4. Multivariate Cox proportional hazard models for the exposed and unexposed cohorts under the age of 3 during the 25-month follow-up period, New France.

\begin{tabular}{|c|c|c|c|c|c|c|c|c|c|}
\hline \multirow[t]{2}{*}{ Risk Factor } & \multicolumn{3}{|c|}{$\begin{array}{c}\text { Model D } \\
\text { Exposed and Unexposed } \\
\mathrm{N}=3,552 \\
\mathrm{n}_{\mathrm{BS}}=2,591\end{array}$} & \multicolumn{3}{|c|}{$\begin{array}{c}\text { Model E } \\
\text { Exposed (1714) } \\
\mathrm{N}=1,071 \\
\mathrm{n}_{\mathrm{BS}}=819\end{array}$} & \multicolumn{3}{|c|}{$\begin{array}{c}\text { Model } \mathrm{F} \\
\text { Unexposed }(1708,1721) \\
\mathrm{N}=2,481 \\
\mathrm{n}_{\mathrm{BS}}=1,772\end{array}$} \\
\hline & HR & RSE & $\mathrm{HR}_{\mathrm{BS}}$ & HR & RSE & $\mathrm{HR}_{\mathrm{BS}}$ & HR & RSE & $\mathrm{HR}_{\mathrm{BS}}$ \\
\hline $\begin{array}{l}\text { Cohort } \\
\text { Exposed } \\
\text { Unexposed } \dagger\end{array}$ & $1.68^{* * *}$ & 0.128 & 1.90 & - & - & - & - & - & - \\
\hline $\begin{array}{l}\text { Residence } \\
\text { Urban } \\
\text { Rural } \dagger\end{array}$ & $2.28^{* * *}$ & 0.132 & 2.14 & $2.19^{* * *}$ & 0.211 & 2.20 & $2.60^{* * *}$ & 0.171 & 2.43 \\
\hline $\begin{array}{l}\text { Sex } \\
\quad \text { Male } \\
\text { Female } \dagger\end{array}$ & $1.50^{* *}$ & 0.126 & 1.50 & 1.36 & 0.199 & 1.36 & $1.59^{* *}$ & 0.164 & 1.67 \\
\hline $\begin{array}{c}\text { Age at Infection/Observ } \\
0-11 \text { months } \dagger \\
12-23 \text { months } \\
24-35 \text { months }\end{array}$ & $\begin{array}{l}0.57^{* * *} \\
0.25^{* * *}\end{array}$ & $\begin{array}{l}0.144 \\
0.186\end{array}$ & $\begin{array}{l}0.52 \\
0.23\end{array}$ & $\begin{array}{l}0.83 \\
0.25^{* * *}\end{array}$ & $\begin{array}{l}0.220 \\
0.285\end{array}$ & $\begin{array}{l}0.73 \\
0.23\end{array}$ & $\begin{array}{l}0.44^{* * *} \\
0.25^{* * *}\end{array}$ & $\begin{array}{l}0.194 \\
0.247\end{array}$ & $\begin{array}{l}0.40 \\
0.21\end{array}$ \\
\hline $\begin{array}{l}\text { Immigrant Status } \\
\text { Immigrant Parent(s) } \\
\text { French Canadian }{ }^{\dagger}\end{array}$ & 1.07 & 0.136 & 1.11 & 1.32 & 0.213 & 1.34 & 0.92 & 0.177 & 0.93 \\
\hline $\begin{array}{l}\text { Age Difference } \\
4+\text { years } \\
<4 \text { years } \dagger\end{array}$ & $1.38^{*}$ & 0.127 & 1.54 & $1.92^{* *}$ & 0.202 & 2.21 & 1.10 & 0.164 & 1.17 \\
\hline $\begin{array}{l}\text { Sibling Survival } \\
\text { Sibling Died } \\
\text { No Death } \dagger\end{array}$ & $1.87^{* *}$ & 0.202 & 1.84 & $2.86^{* * *}$ & 0.247 & 2.58 & 0.82 & 0.418 & 0.82 \\
\hline
\end{tabular}

†Reference category - basis of comparison for the other categories.

$\mathrm{p}<.001^{* * *}, \mathrm{p}<.01^{* *}, \mathrm{p}<.05^{*}$

All models, and especially the exposed cohort, appear to fit the data reasonably well, and the bootstrap hazard ratios $\left(\mathrm{HR}_{\mathrm{BS}}\right)$ are in general agreement with the Cox estimated hazard ratios $(\mathrm{HR})$. The risk factors in the model were all significant, with the exception of the immigrant status of the parents. Generally, the demographic risk factors behaved similarly in the models run separately for the exposed and unexposed cohorts (Models D and F). However, the magnitude of the demographic factors is more pronounced for the unexposed cohort, suggesting that measles was less discriminating than the usual risk factors prevalent in "normal" conditions, buffering out differences in its longterm sequeala. The urban/rural differential was important in all models. In models D and F, exposed and unexposed children residing in the urban towns (Montreal and Quebec City) had over twice the risk of dying during follow-up period $\left(\mathrm{HR}=2.19, \mathrm{p}<.001 ; 2.60, \mathrm{p}<.001\right.$, respectively). ${ }^{5}$

The sex differential in mortality also behaved similarly for exposed and unexposed children, as males had a higher risk of dying in both models. However, the sex difference was only significant among the unexposed cohort $(\mathrm{HR}=1.59, \mathrm{p}<.01$ and 1.36, $\mathrm{p}>.05$, respectively). As would be expected, the risk of death declines with an increasing age at infection/observation in both models during the follow-up period. However, mortality continued to be high for children exposed between 12 and 23 months of age, as the risk of death was not significantly different from infants $(\mathrm{HR}=0.83, \mathrm{p}>.05)$. This indicates that infected toddlers were slow to recover after the acute episode of the epidemic. In contrast, the unexposed cohort follows a typical mortality pattern, as risk was significantly lower at each proceeding age after infancy $(\mathrm{HR}=0.44$ and $0.25, \mathrm{p}<.001)$

5. It should be noted that the regional variation in mortality (i.e., Rural West, Montreal, Quebec City, GQA, and Rural East; see Mazan et al. 2009 and Mazan 2011) disappeared during the post-measles phase (not shown here). Note that in the follow-up period there are fewer events. A fewer number of events could lead to diminished significance when the data is spread thin through the use of too many categories or parameters to be estimated. Although regional mortality was not significantly different for the exposed cohort (except for the urban/rural difference), exposed children in each of the Rural and Urban regions had higher mortality than the unexposed cohorts residing in those same regions (not shown here). 
The familial risk factors show some interesting patterns during the post-measles phase. As with the acute phase of the epidemic, the death of a sibling remained highly significant during the follow-up period. For the exposed cohort, children who had a sibling that died during the acute phase were almost three times more likely to have died during the post-measles phase than exposed children without a death in the family $(\mathrm{HR}=2.86, \mathrm{p}<.001)$. The difference was not significant for the unexposed group ( $\mathrm{HR}=0.92, \mathrm{p}>.05)$. Interestingly, the age difference between siblings in the household had the opposite effect from the previous study (see Mazan 2011). In the present case, exposed children with siblings closer in age (or less than 4 years apart) had almost twice the risk of dying over the follow-up period $(\mathrm{HR}=1.92, \mathrm{p}<.01)$. The effect follows the same direction for the unexposed cohort, but was not significant $(\mathrm{HR}=1.10, \mathrm{p}>.05)$.

As mentioned in the Data and Methods section, the follow-up period was stopped at 25 months past the estimated date of infection because an epidemic occurred between the end of November 1716 and early February of 1717. Table 5 shows the hazard ratios between the exposed and unexposed cohorts during the 25-month and extended follow-up period, which includes the subsequent influenza epidemic. Although exposure to measles may be unrelated to the survival outcome of the epidemic, some interesting patterns emerge with the exposed cohort.

The magnitude of the hazard ratios among females exposed during infancy and toddlerhood increased when extending the follow-up period to include the subsequent epidemic $\left(\operatorname{HR}_{\mathrm{fu}}=2.23, \mathrm{p}<.01 ; 2.21, \mathrm{p}<.01\right)$. This trend reflects the higher probability of death among exposed females during that short time period, as compared to the other cohorts. In terms of the probabilities derived from life tables, females exposed before age 3 had a higher probability of dying between late-November and early-February than unexposed females and both exposed and unexposed males (3.4\% vs. $0.6 \%, 2.2 \%$ and $1.0 \%$, respectively). Exposed males also had an elevated risk compared to the unexposed group, but not to the extent of exposed females. All effects remained the same during the extended follow-up period with the notable exception of the immigrant status of the parents. Interestingly, the effect became significant when including the subsequent epidemic, as it was found that a large portion of deaths were among exposed children who had at least one immigrant parent (particularly, an immigrant father). Although not reported in Table 5, exposed children with at least one immigrant parent had a $52 \%$ higher risk of death than exposed children with Canadian born parents $\left(\mathrm{HR}_{\mathrm{flu}}=1.52, \mathrm{p}<.05\right)$.

\section{Discussion and conclusions}

This study compared the survival of a group of children after exposure to measles with the survival of unexposed cohorts. Overall, children who were exposed to measles before age 3 had a higher probability of death than the unexposed cohort for up to 2 years past the estimated date of infection. The effect remained highly significant when controlling for potential confounding effects. The probability of death was higher for both boys and girls as compared to their counterparts living under normal mortality conditions. Breaking down the results by age at infection, it was found that girls exposed during infancy had a significantly higher risk of dying than unexposed girls, while the corresponding figures were not significantly different for boys. On the other hand, both male and female children

Table 5. Multivariate Cox proportional hazard models for the exposed and unexposed cohorts with the extended follow-up period by age and sex, New France.

\begin{tabular}{|c|c|c|c|c|c|}
\hline \multirow{2}{*}{$\begin{array}{l}\text { Age at Infection } \\
\text { (months) }\end{array}$} & \multirow{2}{*}{ Cohort } & \multicolumn{2}{|c|}{$\begin{array}{l}\text { Model G } \\
\text { Males }\end{array}$} & \multicolumn{2}{|c|}{$\begin{array}{l}\text { Model H } \\
\text { Females }\end{array}$} \\
\hline & & HR & $\mathrm{HR}_{\mathrm{flu}}$ & HR & $\mathrm{HR}_{\mathrm{flu}}$ \\
\hline$<12^{\mathrm{a}}$ & $\begin{array}{l}\text { Exposed } \\
\text { Unexposed } \dagger\end{array}$ & 1.04 & 1.15 & $1.84^{*}$ & $2.23^{* *}$ \\
\hline $12-35^{a}$ & $\begin{array}{l}\text { Exposed } \\
\text { Unexposed } \dagger\end{array}$ & $2.34^{* *}$ & $2.14^{* *}$ & $1.91^{*}$ & $2.21^{* *}$ \\
\hline$<36^{\mathrm{b}}$ & $\begin{array}{l}\text { Exposed } \\
\text { Unexposed } \dagger\end{array}$ & $1.53^{*}$ & $1.56^{*}$ & $1.91^{* *}$ & $2.29^{* * *}$ \\
\hline$<6^{\mathrm{a}}$ & $\begin{array}{l}\text { Exposed } \\
\text { Unexposed } \dagger\end{array}$ & 1.28 & 1.38 & $1.79^{*}$ & $2.16^{* *}$ \\
\hline
\end{tabular}

†Reference category- basis of comparison for the other categories.

$\mathrm{p}<.001^{* * *}, \mathrm{p}<.01^{* *}, \mathrm{p}<.05^{*}$

${ }^{a}$ Controls include: residence, immigrant status, age difference between siblings and dead sibling.

${ }^{\mathrm{b}}$ Controls are the same as in Table 4. 
Mazan: Delayed measles mortality among exposed children who survived the epidemic of 1714-15 in New France

exposed between 12 and 35 months of age had a higher risk of dying than unexposed children; in this case, the effect was slightly stronger for boys. No significant mortality difference was found among children exposed between 36 and 59 months of age.

There were some general similarities found between this study and several modern studies conducted on earlylife exposure (Hull et al. 1983; Aaby et al. 1990, 1993, 1996). Those studies found that children exposed during infancy (before 6 months in the Aaby et al. studies and 12 months in the Hull et al. study) were more likely to die following measles infection than unexposed controls. Mortality increased for up to 36 months past infection, and was higher for exposed infants with and without clinical measles. By comparison, this study found that post-measles mortality for infection during infancy was only significant among females, and that mortality was returning to normal levels before the second year of follow-up. Note also that the above studies did not examine for sex differences in mortality, probably because of the small number of events involved.

This study is also concordant with modern studies showing that measles exposure had long-term consequences. In all cases, exposure remained significant when assessing the effects of the demographic and sibship factors. Aaby et al. (1990) also suggested that "socio cultural confounding" could not account for the long-term difference between the exposed and unexposed cohorts. In one of their early-life studies, they even found no relation between delayed mortality and pre-existing nutrition (Aaby et al. 1996). They suggested that higher delayed mortality was probably related to "biological processes" and concluded that "exposure to the virus itself is a critical factor of delayed mortality." The physiological reasons for the long-term risk are not conclusive, but delayed mortality is likely a combination of viral persistence (never demonstrated), prolonged immune suppression, and Vitamin A deficiency (Clements and Hussey 2004). These adverse effects would make sense in the absence of modern and effective measles treatment such as Vitamin A and antibiotic therapies and vaccination of infected cases.

Interestingly, the strong regional differences that were apparent in the other studies on the 1714-15 measles epidemic (i.e., the Eastern region had higher mortality; see Mazan et al. 2009 and Mazan 2011) disappeared during the post-measles period (not shown here). This change is worth noting because the regional differences provided a means of identifying children who were likely affected by the poor harvests that were reported between 1714 and 1717 (in Eastern Quebec). One possible reason for the diminished regional differences could be the presence of too many regional categories with too few events. Another possibility is that malnutrition did not have much of an influence on exposed children past the acute episode.

It would be premature, however, to suggest that nutritional deficiencies have a limited influence on long-term measles mortality. It is now well recognized that measles complications tend to be more severe in malnourished children, particularly those with Vitamin A deficiency (even a mild deficiency; Perry and Halsey 2004). As there is a synergistic effect between malnutrition and infectious diseases, the relative contribution to acute and delayed mortality can be difficult to delineate (Belamarich and Adam 1998). Further, measles infection can intensify or lead to the onset of malnutrition after infection because of the abnormal loss of protein, increased metabolic demands, and decreased food intake (Moss and Ota 2007).

If both malnutrition and measles compromise the immune system, it is expected that toddlers have higher longterm sequeala from the infection. In this study, both boys and girls infected during this critical period of childhood had higher mortality (see also Mazan 2011). Children at that age may be at a higher risk than infants during crises related to food shortages because they depend more on solid foods and their immune systems are not completely developed, while infants may at least incur some general protection from breastfeeding (Palloni 1990). In many historical populations, the combination of food scarcity and infectious diseases had a strong influence on the long-term survival outcome of children over age 1, but not so much for infants (Bengtsson 2004).

The role of nutrition was also revealed, albeit indirectly, through the use of the immigration status of the parents. Although the risk was still higher for children of immigrant parents, the effect did not reach significance during the follow-up period. If "measles exposure itself" is an important risk factor of delayed mortality, then the difference between exposed children with and without immigrant parents should diminish, as in the normal periods. The difference probably disappeared during the post-measles phase because the most socially disadvantaged (i.e., those from families with fewer resources) were eliminated quickly during the acute phase. Therefore, age at infection and underlying physiological factors were playing a larger role in influencing higher post-measles mortality among exposed children, regardless of parental origin.

During the subsequent influenza epidemic in late 1716, however, the immigrant status of parents became a significant factor. The majority of flu deaths were among exposed children who had at least one immigrant parent 
(particularly fathers). The return of a significant difference may reflect the renewed importance of varying levels of socioeconomic status, mutual support, and access to resources during crisis situations (see Mazan 2011). These social and environmental factors may come into effect with more intensity when the population is compromised by further insults (i.e., another epidemic). Modern studies have also shown that maternal education and socioeconomic status are inversely related to measles mortality (Aaby et al. 1990; Koenig et al. 2001).

As in the prior study on the risk factors of measles mortality, the indirect proxies of intensive exposure in the household (death of a sibling during the acute episode and age difference between siblings) were highly significant in the post-measles models, regardless of age and sex (see Mazan 2011). In contrast to the acute phase, however, the direction of the effect for the age difference between siblings became reversed. Exposed children who had siblings closer in age ( $<4$ years) had a higher risk of dying during the follow-up period (as opposed to a larger age difference in the other study). In the prior study, the significance of a larger age difference probably meant that older siblings (index cases) were introducing the virus into the household and "intensively exposing" their younger siblings (secondary cases). The introduction and transmission of a higher dose of the virus to the younger siblings would increase the severity and risk of death. In the current study, the higher delayed mortality among children who were closer in age could be due to increased sibling competition for limited resources, which may be particularly intense when birth intervals are short.

The apparent sex-difference in long-term mortality among exposed infants was unexpected, because modern studies did not explore this possibility. The sex differential also extended beyond the follow-up period, as exposed girls had higher mortality during the subsequent influenza epidemic. Exposed boys also had an elevated risk above normal, but not to the same degree as females. This trend indicates that exposed girls were at a higher susceptibility of dying from secondary infections than boys following measles exposure.

In the mid-1980s, a higher proportion of children were becoming infected with measles before 9 months of age in some developing countries (Aaby 1995). In 1989, the World Health Organization (WHO) introduced a new high-titre Edmonston-Zagreb measles vaccine (i.e., a strain with a higher dosage of the virus) to induce protective immunity in early life. As it turned out, a series of community studies found that long-term mortality was higher among female recipients of the high-titre vaccine in comparison with those given the Standard Schwarz MediumTitre vaccine (Aaby et al. 1995). Some hypothesized a sex-specific difference in the immune response to the vaccine that would have been "beneficial" for boys, but "detrimental" to girls (Aaby 1995; Clements and Hussey 2004).

Hence, the adverse effect of a higher dose vaccine in modern populations appears similar to the effects of intensive exposure of natural measles in early life in historical Quebec. In that sense, it could be hypothesized that it was intensive exposure in early life that made girls more susceptible to general infections than boys in the long term. Another possible explanation for the difference is selection. Infant mortality is, in general, higher among males, and perhaps the boys were more selected than girls, and thus less likely to die from measles. But more direct causes could also explain the higher mortality among girls, such as the preferential treatment of boys, although there is no evidence of such a sex-differential in early French Canadian society.

In opposition to their earlier claims, Aaby and colleagues $(1995,1996)$ suggested that measles immunization and natural infection might have "beneficial" long-term effects on children. The researchers explained that their previous studies might have "exaggerated" the delayed effect because they compared exposed cases with immunized children (see my Introduction). Generally, the reasoning behind their paradigm shift is unclear. Only a few of the previous studies compared post-measles cases to immunized children. For instance, the studies on early life exposure were not contested, as these studies consisted of comparisons between exposed and unexposed and unimmunized controls (Hull 1988; Aaby et. al. 1990, 1993, 1996).

In closing, a few issues need to be addressed regarding the aforementioned studies. In those studies, the age at infection was relatively high (mean age was over 40 months). In this study, as well, the risk of death among older children exposed past the age of 3 was no different than for the unexposed cohort. A higher mean age at infection is generally the result of vaccination at a younger age and tends to be associated with a lower case fatality rate (Perry and Halsey 2004; Clement and Hussey 2004). Lower case fatality would be expected, as older children are probably more likely to recover from measles, due to a more mature immunological response. The researchers even indicated that the high mean age could explain why no significant post-measles effect was found (Aaby et al. 1996; Dollimore et al. 1997). However, neither of the research teams followed-up on their suggestion.

Another unavoidable problem of the post-measles studies done in West Africa is that they did not control for the potential effects of modern public health knowledge, medical care, and differences in socioeconomic status. These 
Mazan: Delayed measles mortality among exposed children who survived the epidemic of 1714-15 in New France

factors were probably improving over time when the studies took place from the late 1970s onwards, and should have been given further consideration. In addition, effective treatment for measles cases such as, Vitamin A therapy, prompt antibiotic treatment for pneumonia, widespread immunization campaigns, and promotion and prevention measures used by health workers have also contributed to a lower case fatality rate in the past 25 years (Perry and Halsey 2004).

In summary, public health interventions could have contributed to a better survival outcome for the children in those studies. In historical Quebec, on the other hand, modern medical knowledge, treatments, and immunization campaigns did not exist. The conditions during that time were pristine or untouched by the influences these modern advancements in the prevention and treatment of disease. Therefore, the study of measles in pre-industrial Quebec helps provide some closure on the debate of the alleged exaggeration of post-measles mortality. Although further studies are needed to confirm these findings, this study has clearly shown that there was an increased risk in longterm mortality among children exposed to measles.

\section{References}

Aaby, P. 1995. Assumptions and contradictions in measles and measles immunization research: Is measles good for something? Social Science and Medicine 5:673-686.

Aaby, P., and C.J. Clements. 1989. Measles immunization research: A review. Bulletin of the World Health Organization 67:443-448.

Aaby, P., J. Bukh, I.M. Lisse, and M.C. Da Silva. 1990. Delayed excess mortality after exposure to measles during the first six months of life. American Journal of Epidemiology 132:49-63.

Aaby, P., M. Anderson, and K. Knudsen. 1993. Excess mortality after early exposure to measles. International Journal of Epidemiology 22:156-162.

Aaby, P., B. Samb, F. Simondon, A.M. Seck, K. Knudsen, and H. Whittle. 1995. Non-specific beneficial effect of measles immunisation: Analysis of mortality studies from developing countries. British Medical Journal 311:481-485.

Aaby, P., M. Anderson, and K. Knudsen. 1996. Nutritional status and delayed mortality following early exposure to measles. Epidemiology and Infection 117:525-531.

Aaby, P., B. Samb, M. Anderson, and F. Simondon. 1996. No long-term excess mortality after measles infection: A community study. American Journal of Epidemiology 143:1035-1041.

Amorevieta-Gentil, M. 2010. Les niveaux et les facteurs déterminants de la mortalité infantile en Nouvelle-France et au début du Régime Anglais (1621-1779). PhD diss. Département de Démographie, Université de Montréal.

Belamarich, P.R., and H.M. Adam. 1996. Measles and malnutrition. Pediatrics in Review 19:70-71.

Bengtsson, T., C. Campbell, and J.Z. Lee. 2004. Life Under Pressure: Mortality and Living Standards in Europe and Asia, 1700-1900. Cambridge, MA: MIT Press.

Blossfeld, H., A. Hamerle, and K.U. Mayer. 1989. Event History Analysis: Statistical Theory and Application in the Social Sciences. New Jersey: Lawrence Erlbaum Associates.

Breslow, N.E., and N.E. Day. 1987. Statistical Methods in Cancer Research. Vol. II, The Design and Analysis of Cohort Studies. IARC Scientific Publication No. 82. Lyons: IARC Press.

Charbonneau, H., B. Desjardins, A. Guillemette, Y. Lardry, J. Légaré, and F. Nault. 1993. The First French Canadians: Pioneers in the St. Lawrence Valley. Newark: University of Delaware Press.

Chen, R.T., R. Weierbach, Z. Bisoffi, F. Cutts, P. Rhodes, S. Ramaroson, et al. 1994. A “post-honeymoon period” measles outbreak in Muyinga Sector, Burundi. International Journal of Epidemiology 23:185-193.

Clements, C.J., and G.D. Hussey. 2004. Measles, in The Global Epidemiology of Infectious Diseases, edited by C.J.L. Murray, A.D. Lopez, and C.D. Mathers. Geneva: WHO. 
Desjardins, B. 1996. Demographic aspects of the 1702-1703 smallpox epidemic in the St-Lawrence valley. Canadian Studies in Population 27:49-67.

Dollimore, N., F. Cutts, F.N. Binka, D.A. Ross, S.S. Morris, and P.G. Smith. 1997. Measles incidence, case fatality, and delayed mortality in children with or without vitamin A supplementation in rural Ghana. American Journal of Epidemiology 146:646-654.

Duffy, J. 1953. Epidemics in Colonial America. Baton Rouge: Louisiana State University Press.

Elandt-Johnson, R.C., and N.L. Johnson. 1980. Survival Models and Data Analysis. New York: John Wiley and Sons.

Esteve, J., E. Benhamou, and L. Raymond. 1994. Statistical Methods in Cancer Research. Vol. IV, Descriptive Epidemiology. IARC Scientific Publication No. 128. Lyons: IARC Press.

Gagnon, A., and R. Mazan. 2009. Does exposure to infectious diseases in infancy affect old age mortality? Evidence from a pre-industrial population. Social Science and Medicine 68:1609-1016.

Garenne, M., and P. Aaby. 1990. Patterns of exposure and measles mortality in Senegal. Journal of Infectious Diseases 161:1088-1094.

Hull, F. 1988. Increased measles mortality in households with multiple cases in the Gambia, 1981. Review of Infectious Diseases 10:463-467.

Hull, H.F., P.J. Williams, and F. Oldfield. 1983. Measles mortality and vaccine efficacy in rural West Africa. The Lancet 321:972-975.

Joshi, A.B., E.T. Luman, R. Nandy, B.K. Subedi, B.L. Jayantha, J.B. Liyanaga, and F. Wierzbat. 2009. Measles deaths in Nepal: Estimating the national case-fatality ratio. Bulletin of the World Health Organization 87:456-465.

Koenig, M.A., D. Bishai, and M.A. Khan. 2001. Health interventions and health equity: The example of measles vaccination in Bangladesh. Population and Development Review 27:283-302.

Légaré, J. 1988. A population register for Canada under the French regime: Context, scope, content, and applications. Canadian Studies in Population 15:1-16.

Mazan, R. 2011. Risk factors of mortality among French Canadian children during the measles epidemic of 1714-15. Genus 67:31-56.

Mazan, R., and A. Gagnon. 2007. Familial and environmental influences on longevity in a pre-industrialized population. Population-E 62(2):271-292.

Mazan, R., A. Gagnon, and B. Desjardins. 2009. The measles epidemic of 1714-1715 in New France. Canadian Studies in Population 36:295-323.

Murray, G.D., and A.D. Cliff. 1977. A stochastic model for measles epidemics in a multi-region setting. Transactions of the Institute of British Geographers 2:158-174.

Namboodiri, K., and C.M. Suchindran. 1987. Life Table Techniques and Their Applications. San Diego: Academic Press.

Perry, R.T., and N.A. Halsey. 2004. The clinical significance of measles: A review. The Journal of Infectious Diseases 189(Suppl 1): S4-S16.

Singer, J.D., and J.B. Willett. 2003. Applied Longitudinal Data Analysis: Modeling Change and Event Occurrence. New York: Oxford University Press.

Wolfson, L.J., R.F. Grais, F.J. Luquero, M.E. Birmingham, and P.M. Strebel. 2009. Estimates of measles case fatality ratios: A comprehensive review of community-based studies. International Journal of Epidemiology 38:192-205. 